\title{
Chinese parents' evaluation of children's temperament differences:Factor Analysis Based on PTQ Child Temperament Scale
}

\author{
Yang Han \\ Institute of Psychology Chinese Academy of Sciences, \\ Beijing 100101; Department of Psychology, University of \\ Chinese Academy of Sciences, Beijing 100049 \\ hanyang9822@hotmail.com
}

\begin{abstract}
[Objective] Explore the dimensions and factor structure of children's temperament described by Chinese parents, Reveal the characteristics and reasons of children's temperament that parents pay attention to, Explore the changing trend of parents' assessment of children's temperament. [Methods] The PTQ temperament scale was used to investigate 1000 children, and exploratory factor analysis(EFA) and confirmatory factor analysis(CFA) was adopted to examine its construction. [Results] EFA showed that five dimensions could be summarized, which were negative emotions and adaptability, concentration, activity level, flexibility and self-control, shyness or social withdrawal. Five factors cumulatively explained $33.485 \%$ of the variance. The CFA supported the five-dimension model and main fit index included $\chi^{2} / \mathrm{df}=2.79, \mathrm{GFI}=0.876, \mathrm{CFI}=0.843$, IFI $=0.844$, AGFI $=0.850$, RMSEA $=0.060$. Each item's factor loading valued between 0.397 and 0.778 , and the correlation coefficient within 5 dimensions ranged from 0.133 to 0.702 . [Conclusion] The five-dimension model is structurally clear-stated. The results show that in the minds of Chinese parents, the dimension of children temperament of five factors is more stable. At the same time, the distribution of children's temperament structure shows a dynamic trend. It is suggested that the educators and parents of Chinese children should fully consider the uniqueness of Chinese culture and social development, and develop more socially adaptive, flexible and open parenting concepts and education methods according to the temperament and personality characteristics of Chinese children.
\end{abstract}

\section{CCS CONCEPTS}

- ; Social and professional topics $\rightarrow$ Professional topics; Management of computing and information systems;

\section{KEYWORDS}

children, temperament type, Questionnaire, structural analysis, Parental assessment

\footnotetext{
${ }^{*}$ Corresponding author

Permission to make digital or hard copies of all or part of this work for personal or classroom use is granted without fee provided that copies are not made or distributed for profit or commercial advantage and that copies bear this notice and the full citation on the first page. Copyrights for components of this work owned by others than ACM must be honored. Abstracting with credit is permitted. To copy otherwise, or republish, to post on servers or to redistribute to lists, requires prior specific permission and/or a fee. Request permissions from permissions@acm.org.

ICETT 2021, April 14-16, 2021, Macau, China

(C) 2021 Association for Computing Machinery.

ACM ISBN 978-1-4503-8966-2/21/04 ..\$15.00

https://doi.org/10.1145/3463531.3463551
}

\author{
Yuqing Zhang* \\ Institute of Psychology Chinese Academy of Sciences, \\ Beijing 100101; Department of Psychology, University of \\ Chinese Academy of Sciences, Beijing 100049 \\ zhangyq@psych.ac.cn
}

\section{ACM Reference Format:}

Yang Han and Yuqing Zhang. 2021. Chinese parents' evaluation of children's temperament differences:Factor Analysis Based on PTQ Child Temperament Scale. In 2021 7th International Conference on Education and Training Technologies (ICETT 2021), April 14-16, 2021, Macau, China. ACM, New York, NY, USA, 5 pages. https://doi.org/10.1145/3463531.3463551

\section{INTRODUCTION}

Children's temperament refers to the innate way of behavioral response, which is an important individual difference in children's development. It is of great significance to understand and predict children's personality and social development, especially in the long-term social interaction. Therefore, in recent years, the study of children's temperament has attracted the special attention of psychologists.

The study of children's temperament has become one of the hotspots of international development psychology. Gesell and shirly (1928) [1], pioneers of the study of children's temperament, believe that temperament is the core of children's personality and changes by children's social experience. In recent decades, Thomas and chess (1977) [2], brazalton (1978) [3], Rothbart (1981) [4], Strelau (1983) [5], Buss and Plomin (1984) [6], Kagan (1986) [7], Sanson (1994) [8], Caspi (1995) [9] and Martin (1997) [10], etc. have studied children's temperament from different perspectives and put forward their own classification types. Among them, Thomas and Chess, American child psychologists, led the New York Longitudinal Study (NYLS) in 1956. Based on the behavior observation of newborn babies and interviews with parents and teachers, they put forward a nine-dimensional temperament structure and divided three temperament types, which has important practical value and can better explain the interaction between parent-child relationship and environment. The parent temperamental questionnaire (PTQ), which was compiled by Thomas and chess in 1977, plays an important role and authority in the research of children's temperament, and has become a widely used tool in the research of children's temperament in the world.

Martin (1994) [11] and others used Thomas and chess's scale to analyze the factors of children's temperament measurement, and obtained seven dimensions of temperament structure; Zhang Yuqing (1999) [12] used Thomas and chess scale to test children in Chinese mainland, and obtained six dimensions of temperament structure. It can be seen that the survey results of different countries and regions have certain differences. The reason is that these nine dimensions originate from diagnosis, which shows the relative concept overlap, and then causes the inconsistency in cross-cultural 
researches [13]. On the research progress of children's temperament in different countries and regions, kohnstam introduced the research results of 43 children's temperament psychologists from 11 European and American countries in children's temperament [14]. Kohnstam pointed out that "we urgently welcome the systematic research results of children's temperament from Eastern countries". It can be seen that the study of the characteristics and development rules of children's temperament structure in China and the exploration of relevant influencing factors will not only help to provide theoretical basis for the individualized early education of children in China, but also help to promote the systematic and comprehensive research of children's temperament in different cultures and regions.

Based on the important value and far-reaching significance of the above research on children's temperament structure characteristics in China, this study intends to use Thomas and chess's children temperament parent questionnaire to explore the characteristics and development trend of children's temperament structure in kindergartens (6 years old) assessed by parents. By exploring the characteristics of children's temperament that parents pay attention to, as well as the changes of parents' attention to children's temperament in recent 20 years with the social transformation and changes, it is of great practical significance for understanding which personality qualities and personality characteristics parents pay more attention to in the process of raising children, exploring the family education factors that affect children's psychological development, and promoting and cultivating children's perfect personality and healthy psychology.

\section{METHODS}

\subsection{Subjects}

In order to sample more widely and representatively, the subjects of the questionnaire were 1173 children aged 6 from 14 kindergartens in Kunming City, Zibo City, Jincheng City, Jinan City, Qingdao City, Taiyuan City, Xinzhou City and Zhangjiakou City in China, 1173 questionnaires were distributed and 1151 valid questionnaires were collected.

\subsection{Research tool}

2.2.1 Parent Temperament Questionnaire, PTQ. The "Parent Temperament Questionnaire (PTQ)" compiled by Thomas and Chess in 1977 proposed a nine-dimensional temperament structure, namely: Activity Level, Rhythmicity, Approach-Withdrawal, Adaptabilit, Threshold of Response, Intensity of Response, Mood, Persistence, and Distractively. In the 1980s, Xu Qingming of Taiwan University translated the scale into Chinese and revised it in Chinese Taiwan. In 1992, Zhang Yuqing and others revised the scale to apply to Chinese mainland. There are 72 items in the scale (for example, being very active in the bath and splashing around when taking a bath). Each item has 7 grades and the scores are 1, 2, 3, 4, 5, 6 and 7 respectively. The questionnaire was filled in by parents who knew their children well. There were instructions and methods to fill in at the beginning of the questionnaire.

\subsection{Statistical analysis method}

In this study, SPSS16.0 statistical software was used for exploratory factor analysis, and covariance structure model was used to explore the dimension and structure of children's temperament. Amos23.0 was used for confirmatory factor analysis.

\section{RESULTS}

\subsection{Exploratory factor analysis results}

Firstly, KMO statistics and Bartlett sphere test were used to examine whether the scale is suitable for exploratory factor analysis, If KMO value is greater than 0.7 and Bartlett's spherical test is significant, the scale is suitable. The results of factor analysis showed that KMO value was 0.918 , and Bartlett spherical test reached 0.000 significance level, which indicated that the 72 items of the scale could be further analyzed.

500 samples were randomly selected from 1153 samples, and 72 items of parents' evaluation of children's temperament scale were analyzed by principal factors. After Varimax rotation, a structure consisting of 5 factors was obtained, as shown in Table 1 . This structure includes 27 items, which explains $33.485 \%$ of variance. In order to test the reliability of the structure, the analysis results of direct oblimin rotation and promax rotation are used to obtain the same factor structure as varimax rotation, which prove that the structure is stable and reliable. The five factors of the structure obtained in this paper are named as follows: Negative emotions and adaptability, concentration, activity level, flexibility and self-control, and shyness or social withdrawal.

Among the above five factors, the content of factor 1, namely "negative emotion and adaptability", mainly includes frustration, irritability, uncooperative and children's adaptation to new environment or new stimulus; The content of factor 2, namely "concentration", mainly describes the problems related to concentration; The content of factor 3, namely "activity level", refers to the amount and speed of children's daily activities; The content of factor 4, namely "flexibility and self-control", mainly describes whether parents consider their children easy to discipline; The content of factor 5 , namely "shyness or social withdrawal", mainly describes children's fear or withdrawal reaction to the new environment.

\subsection{Confirmatory factor analysis results}

Randomly select 500 sample data different from exploratory factor analysis from 1151 samples, and use 27 items retained by exploratory factor analysis as analysis indicators to establish a 5factor first-order model for confirmatory factor analysis. The results showed that the fitting indexes of GFI, CFI, IFI and AGFI were all above 0.80 , which met the requirements, indicating that the five factor structure obtained by exploratory factor analysis was supported by confirmatory factor analysis. The values of each parameter are as follows: $\chi^{2} / \mathrm{df}=2.79, \mathrm{GFI}=0.876, \mathrm{CFI}=0.843$, IFI $=$ 0.844 , AGFI $=0.850$, RMSEA $=0.060$. The standard load coefficient of each item in its own factor is between 0.397 and 0.778 (Table 2), and the correlation coefficient among the five factors is between 0.133 and 0.702 . The first-order factor structure model is shown in Figure 1 
Table 1: Exploratory factor analysis results

\begin{tabular}{|c|c|c|c|c|c|c|c|c|c|c|}
\hline & \multicolumn{2}{|c|}{$\begin{array}{l}\text { Negative emotions } \\
\text { and adaptability }\end{array}$} & \multicolumn{2}{|c|}{ concentration } & \multicolumn{2}{|c|}{ activity level } & \multicolumn{2}{|c|}{$\begin{array}{l}\text { flexibility and } \\
\text { self-control }\end{array}$} & \multicolumn{2}{|c|}{$\begin{array}{l}\text { shyness or social } \\
\text { withdrawal }\end{array}$} \\
\hline & $\begin{array}{l}\text { Title } \\
\text { number }\end{array}$ & $\begin{array}{l}\text { Loadings } \\
\text { value }\end{array}$ & $\begin{array}{l}\text { Title } \\
\text { number }\end{array}$ & $\begin{array}{l}\text { Loadings } \\
\text { value }\end{array}$ & $\begin{array}{l}\text { Title } \\
\text { number }\end{array}$ & $\begin{array}{l}\text { Loadings } \\
\text { value }\end{array}$ & $\begin{array}{l}\text { Title } \\
\text { number }\end{array}$ & $\begin{array}{l}\text { Loadings } \\
\text { value }\end{array}$ & $\begin{array}{l}\text { Title } \\
\text { number }\end{array}$ & $\begin{array}{l}\text { Loadings } \\
\text { value }\end{array}$ \\
\hline & 44 & 0.659 & 5 & 0.657 & 24 & 0.688 & 71 & 0.603 & 10 & 0.702 \\
\hline & 43 & 0.600 & 14 & 0.580 & 1 & 0.652 & 69 & 0.563 & 4 & 0.643 \\
\hline & 54 & 0.595 & 23 & 0.577 & 18 & 0.643 & 59 & 0.557 & 46 & 0.567 \\
\hline & 36 & 0.578 & 34 & 0.553 & 45 & 0.57 & 58 & 0.537 & 30 & 0.513 \\
\hline & 66 & 0.559 & 13 & 0.550 & & & & & & \\
\hline & 51 & 0.554 & 3 & 0.534 & & & & & & \\
\hline & 68 & 0.528 & 6 & 0.525 & & & & & & \\
\hline & 40 & 0.523 & & & & & & & & \\
\hline Eigenvalues & 9.185 & & 7.333 & & 3.257 & & 2.249 & & 2.086 & \\
\hline
\end{tabular}

Table 2: Standard load factor of confirmatory factor analysis project to its factor

\begin{tabular}{|c|c|c|c|c|c|c|c|c|c|}
\hline \multicolumn{2}{|c|}{$\begin{array}{l}\text { Negative emotions and } \\
\text { adaptability }\end{array}$} & \multicolumn{2}{|c|}{ concentration } & \multicolumn{2}{|c|}{ activity level } & \multicolumn{2}{|c|}{$\begin{array}{l}\text { flexibility and } \\
\text { self-control }\end{array}$} & \multicolumn{2}{|c|}{$\begin{array}{l}\text { shyness or social } \\
\text { withdrawal }\end{array}$} \\
\hline $\begin{array}{l}\text { Title } \\
\text { number }\end{array}$ & $\begin{array}{l}\text { load } \\
\text { coefficient }\end{array}$ & $\begin{array}{l}\text { Title } \\
\text { number }\end{array}$ & $\begin{array}{l}\text { load } \\
\text { coefficient }\end{array}$ & $\begin{array}{l}\text { Title } \\
\text { number }\end{array}$ & $\begin{array}{l}\text { load } \\
\text { coefficient }\end{array}$ & $\begin{array}{l}\text { Title } \\
\text { number }\end{array}$ & $\begin{array}{l}\text { load } \\
\text { coefficient }\end{array}$ & $\begin{array}{l}\text { Title } \\
\text { number }\end{array}$ & $\begin{array}{l}\text { load } \\
\text { coefficient }\end{array}$ \\
\hline 44 & 0.716 & 5 & 0.590 & 24 & 0.778 & 71 & 0.711 & 10 & 0.482 \\
\hline 43 & 0.535 & 14 & 0.696 & 1 & 0.530 & 69 & 0.575 & 4 & 0.397 \\
\hline 54 & 0.496 & 23 & 0.612 & 18 & 0.701 & 59 & 0.762 & 46 & 0.702 \\
\hline 36 & 0.501 & 34 & 0.561 & 45 & 0.566 & 58 & 0.736 & 30 & 0.777 \\
\hline 66 & 0.421 & 13 & 0.577 & & & & & & \\
\hline 51 & 0.503 & 3 & 0.571 & & & & & & \\
\hline 68 & 0.400 & 6 & 0.439 & & & & & & \\
\hline 40 & 0.450 & & & & & & & & \\
\hline
\end{tabular}

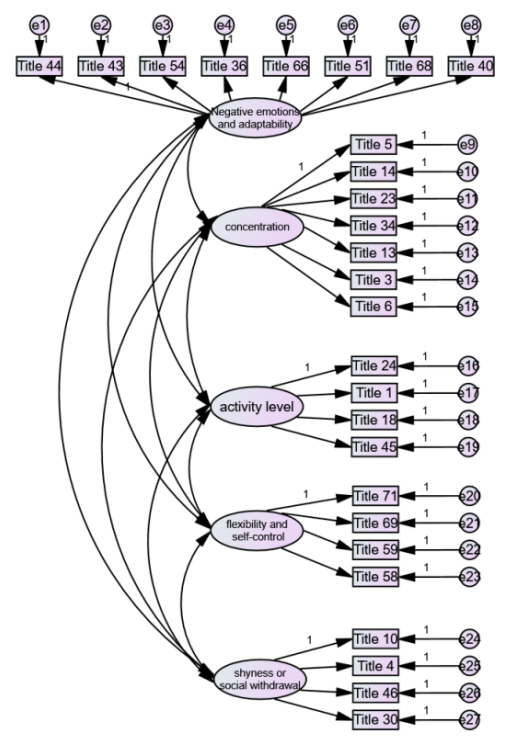

Figure 1: First order factor structure model

\section{DISCUSSION}

In this study, an exploratory factor analysis was carried out on the parents' evaluation of children's temperament questionnaire, and a structure of five factors was summarized, which was verified by confirmatory factor analysis. The characteristics of the five dimensions and the different dimensions that reflect the attitudes and ideas of parents towards their children are discussed as follows:

\subsection{Characteristics of 5-dimensional factors and parents' educational philosophy}

4.1.1 Negative emotions and adaptability. "Negative emotions and adaptability" are the temperament characteristics that parents value or concerned most about their children. Emotion is the core of defining temperament [15]. If the problems caused by negative emotions in preschool children are not promptly intervened, it may have adverse effect on the children's future academic performance, interpersonal relationships and professional performance [16]. Children's ability to adjust and adapt to negative emotions is of great significance to children's development in social interaction and the establishment of the key psychological mechanism to adapt to society. Family environment is an important factor affecting children's emotional development. Parents' attention to children's negative 
emotions and adaptability reflects that Chinese parents is paying more attention to children's social emotional development and socialization ability training as the education of children's mental health knowledge rises in China.

4.1.2 Concentration. "Concentration" is an important temperament characteristic that parents think of their children. This dimension describes the problems related to attention, and shows that Chinese parents highly value children's attention. Attention is an important channel for information acquisition. All information that children obtain from the outside world needs attention to enter the brain. The preschool period is a critical period for attention development. Inattention is equivalent to closing the channel for acquiring knowledge. In the 2016 Survey Report on Focus Issues of Family Education in China [17], among the 4-6-year-old families, the lack of attention in learning ranks the third. In addition, Liu Wen et al. (2005) [13] concluded that "concentration is an important dimension of Chinese children's temperament" based on the structure of children's temperament assessed by teachers. It is consistent with the parents' assessment of "concentration" as an important temperament dimension of Chinese children. This result is related to the fact that Chinese parents always pay close attention to their children's academic performance. Studies have shown that compared with Western countries, Chinese parents describe their children more frequently as being not serious enough, inattentive in class, easily distracted, not having enough ambition, not being hard enough, and non-achievement-oriented [18].

4.1.3 Activity level. Moderate and high-intensity physical activity has a significant positive correlation with the physical growth of preschool children [19]. The factor of "activity level" indicates that Chinese parents pay more attention to their children's activity in playgrounds, indoor and outdoor.

4.1.4 Flexibility and self-control. "Flexibility and self-control" is also one of the parents in our country that pay more attention to children's temperament and regard it as an important part of good family education. Studies have shown that the development of self-control is more conducive to improving academic performance than IQ. This is consistent with the "concentration" factor discussed above, which indicates that Chinese parents pay more attention to their children's academic performance.

4.1.5 Shyness or social withdrawal. "Shyness or social withdrawal" refers to a kind of behavior of low communication frequency, passive communication or separation from the group, often accompanied by emotional experience such as loneliness [20]. Shyness or social withdrawal has a certain impact on children's social adaptation. Chinese parents pay more attention to children's temperament structure, which shows that parents are more concerned about whether children can gradually master social norms, correctly handle interpersonal relationships, learn self-control and adjustment, and develop better social adaptability.

\subsection{Trend of the change of children's temperament structure in recent around 20 years}

The survey of this study was completed in 2017, compared with the factor analysis of temperament structure of Chinese children [12] conducted by Zhang Yuqing (1997). The temperament structure of Chinese children was obtained by comparing the two surveys, as shown in Table 3,

Comparing the results of the survey in 2017 and 1997, the discussion is as follows:

The five factors of the temperament structure of Chinese children obtained in this study is highly consistent with the first five factors of the six-factor temperament structure obtained by Zhang Yuqing (1997). In addition, in the exploratory factor analysis stage, this study attempts to construct 5-Dimensional and 6-dimensional factor structures respectively, and the results show that in the exploratory factor analysis stage, the structures of the two dimensions can be established, However, in the further confirmatory factor analysis, the fitting parameters of five-dimensional factors are better, In this study, the five-dimensional factor structure was selected as the final research result. Between the two decades, the temperament structure obtained by the two factor analyses has high consistency, which shows that a stable dimension of children's temperament in minds of Chinese parents, and the dimension of children's temperament of five factors is more stable.

This study is consistent with the factor composition obtained by Zhang Yuqing's two factor analysis in 1997, but the ratio and order of explaining the total variance of each factor are different, which shows that in the minds of Chinese parents, the composition of children's temperament structure in China is generally stable, but with the change of economic development, thinking mode and educational concept, the parenting concept of Chinese parents and the focus on children's temperament dimension have changed. For example, during the past 20 years, the highlight of Chinese parents has transformed from "attention concentration"(highly related to children's learning) into "negative emotions and adaptability"(more comprehensively reflect children's psychological development level and social adaptability), which indicates that the comprehensive ability of more diversified and more social adaption is preferred in the children cultivation, instead of single learning ability, despite that Chinese parents still regard children's learning ability as important quality.

\section{CONCLUSION}

To sum up, from the recognition of Chinese parents, the dimension of children's temperament of five factors is more stable. The conclusion suggests that children's psychological researchers and Chinese parents should fully consider the uniqueness of China's cultural and social development in the exploration of early childhood education theory and the implementation of family education. It is necessary to carry out in-depth and local exploration according to the temperament and personality characteristics of Chinese children, so as to better promote the physical and mental development of Chinese children.

The composition of children's temperament structure in China is relatively stable. With the development of society and the progress 
Table 3: Trend of the change of children's temperament structure in recent around 20 years

\begin{tabular}{lllll}
\hline & 2017 & $\begin{array}{l}\text { Total Variance } \\
\text { Explained }\end{array}$ & 1997 & $\begin{array}{l}\text { Total Variance } \\
\text { Explained }\end{array}$ \\
\hline Factor 1 & $\begin{array}{l}\text { Negative emotions and } \\
\text { adaptability }\end{array}$ & $8.06 \%$ & Concentration & $9.1 \%$ \\
Factor 2 & Concentration & $7.69 \%$ & Flexibility and self-control & $6.2 \%$ \\
Factor 3 & Activity level & $7.11 \%$ & Negative emotions & $4.5 \%$ \\
Factor 4 & Flexibility and self-control & $6.62 \%$ & Shyness or social withdrawal & $2.9 \%$ \\
Factor 5 & Shyness or social withdrawal & $4.00 \%$ & Activity level and Threshold of & $2.9 \%$ \\
Factor 6 & - & - & Response & Rhythmicity \\
\hline
\end{tabular}

of educational ideas, the distribution of structure presents dynamic attribute. In view of this stable but dynamic feature, it is suggested that Chinese children educators and parents should keep pace with the times in educating and parenting, and constantly develop more adaptable, flexible and open-mind parenting concepts and methods.

\section{REFERENCES}

[1] Gesell A. Growth potency and infant personality in infancy and human growth New York: Macmillan, 1928. 355-378

[2] Thomas A,Chess S. Temperament and development. New York: Bruner/Mazel,1977.3-5

[3] Brazalton. Infant and mother.Translated by Zhang P Q, Chen G M. Beijing: Beijing Science \& Techonology Press,1989,3

[4] Rothbart M K. Measurement of temperament in infancy. Child Development,1981,52(2):569-578

[5] Strelau J. Temperament,personality,activity.New York: Academic Press,1983.4-6

[6] Buss H,Plomin R. Temperament:Early developing personality traits.Hillsdale N. $\mathrm{J}:$ E rlbaum, 1984.5

[7] Kagan J. Temperament inhibition in early childhood.In: Plomin R,Dunn $\mathrm{J}$ (Eds).The study of temperament:Changes,continuities and challenges. Hillsdale,NJ:Erbaum,1986.53-65

[8] Sanson A V,Smart D F,Prior M,Pedlow R. The structure of temperament from three to seven years:Age,sex and socidemographic influeness. Merrill-Palmer Quarterly,1994,40:233-252

[9] Caspi A., Henry B,McGee R O,Moffitt T E,Sliva P A. Temperamental origins of and adolescent behavior problem: From age to age fifteen. Child Development,1995,66(1):55-68
[10] Martin R P. The temperament assessment battery for children revised.phD Dissertation.Athens:The University of Georgia,1997.13

[11] Martin.R.P..Wisenbaker.J..\& Hueeunen. M.(1994).Review of factor analytic studies of temperament measures based on the Thomas-Chess structural model:Implications for the Big Five. In C.F.Halverson.G.A.Kohnstamm. \& R.P.Martin(Eds).The developing structure of temperament and personality from infancy to adulthood(pp.157-172).Hilsdale. NJ:Erlbaum.

[12] Factor analysis for the structure of Chinese children's temperament based on Thomas and Chess parent and teacher's questionnaires. Chinese Journal of Pediatrics. 1999,)3(:1-10

[13] Liu Wen, Yang Li Zhu. Temperament structure of children aged 3-9 based on teacher evaluation. Acta psychologica Sinica. 2005, 37)1(:67-72

[14] Kohnstam G A. Temperament in childhood. New York: John Wiley \& Sons Ltd,1989,3

[15] Martin R P,Bridger R C,Temperament assessment battery for children revised. PhD.Disseration. Athens: The University of Geogria,1997.29

[16] Hua Mizhi, Zhou Renlai. Application of preschool behavior and Emotion Scale in Chinese preschool children [J]. Chinese Journal of clinical psychology, 2012, 20(3):320-324

[17] 2016 survey report on the focus of China's family education [J]. China's familyschool cooperative education, 2016, 0(3):82-85

[18] Yuching Zhang, Geldolph Kohnstamm, Anne-Marie Slotboom, Eric Elphick, Ping Chung. Chinese and Dutch Parents' Perceptions of Thier Children's Personality. The Journal of Genetic Psychology, 2002,163(2):165-178.

[19] Zhao Guangluo, Wang Ru, etc.. The effect of physical activity on the physical growth of preschool children[J].Journal of Shanghai University of Sport, 2017, 41) 04(:65-69

[20] Li Yan, Lu Fang, Chen Lu. Social adaptation of withdrawn children and its influencing factors. Elementary and secondary education abroad, 2014)2(:27-34 